\title{
Solar Radiation Received by Slopes Using COMS Imagery, a Physically Based Radiation Model, and GLOBE
}

\author{
Jong-Min Yeom, ${ }^{1}$ You-Kyung Seo, ${ }^{1}$ Dong-Su Kim, ${ }^{2}$ and Kyung-Soo Han ${ }^{3}$ \\ ${ }^{1}$ Korea Aerospace Research Institute, 169-84 Gwahak-ro, Yuseong-gu, Daejeon 305-806, Republic of Korea \\ ${ }^{2}$ Korea Meteorological Agency, 169-84 Gwahak-ro, Yuseong-gu, Daejeon 305-806, Republic of Korea \\ ${ }^{3}$ Department of Spatial Information Engineering, Pukyong National University, Busan 608-737, Republic of Korea
}

Correspondence should be addressed to Jong-Min Yeom; yeom.jongmin@gmail.com

Received 27 November 2015; Accepted 3 February 2016

Academic Editor: Chiman Kwan

Copyright (C) 2016 Jong-Min Yeom et al. This is an open access article distributed under the Creative Commons Attribution License, which permits unrestricted use, distribution, and reproduction in any medium, provided the original work is properly cited.

\begin{abstract}
This study mapped the solar radiation received by slopes for all of Korea, including areas that are not measured by ground station measurements, through using satellites and topographical data. When estimating insolation with satellite, we used a physical model to measure the amount of hourly based solar surface insolation. Furthermore, we also considered the effects of topography using the Global Land One-Kilometer Base Elevation (GLOBE) digital elevation model (DEM) for the actual amount of incident solar radiation according to solar geometry. The surface insolation mapping, by integrating a physical model with the Communication, Ocean, and Meteorological Satellite (COMS) Meteorological Imager (MI) image, was performed through a comparative analysis with ground-based observation data (pyranometer). Original and topographically corrected solar radiation maps were created and their characteristics analyzed. Both the original and the topographically corrected solar energy resource maps captured the temporal variations in atmospheric conditions, such as the movement of seasonal rain fronts during summer. In contrast, although the original solar radiation map had a low insolation value over mountain areas with a high rate of cloudiness, the topographically corrected solar radiation map provided a better description of the actual surface geometric characteristics.
\end{abstract}

\section{Introduction}

Renewable energy has attracted considerable attention as we attempt to meet the dual goals of reducing greenhouse gas emissions and securing energy resources, while limiting future extreme weather and climate impacts, and ensuring reliable, timely, and cost-efficient delivery of energy [1]. Among renewable energy sources such as wind and solar energies, solar energy is one of the oldest, cleanest, and most reliable renewable energy source. In the case of solar radiation, there are many different applications: analysis of the thermal load on buildings, solar energy collecting systems, crop growth models, atmospheric energy balance studies, and so forth [2], with the result that the solar radiation levels form the most important parameter for solar energy applications [3]. Therefore, an accurate model predicting the levels of solar irradiation is required [4].
The incident of solar radiation on the Earth's surface has high temporal and spatial variations, affected by the environmental system, indicating that the areas in which solar energy capture is efficient must be determined. Although pyranometer measurements could accurately determine the incident solar radiation in the desired locations, the number of such stations is usually insufficient to provide solar radiation data for the desired areas; the spatial representativeness is low [5]. An alternative solution to this problem is to use a physical model to derive direct normal irradiation, by integrating satellite data [6]. Use of satellite data has an advantage over radiation data from ground-based measurements in terms of better temporal and spatial coverage [7]. Zhang et al. [8] presented a practical scheme to create the Global LA Surface Satellite (GLASS) incident shortwave radiation (ISR) and photosynthetically active radiation (PAR) products. These were developed using a look-up table (LUT) containing data 
from polar and geostationary satellites for global coverage. He et al. [9] and Bisht and Bras [10] developed a physics-based algorithm for estimating incident shortwave radiation using satellite data, demonstrating its usefulness in a separate but related context. The use of these data, in conjunction with quality solar ground datasets and other meteorological data, has become an effective way of developing site-time specific solar resource assessment over large areas. In particular, deriving solar radiation data from geostationary satellite images is advantageous for solar resource characterization over large areas [11]. Satellite imagery is useful for monitoring the complex variations of cloud because clouds are the most important atmospheric phenomena influencing the spatial and temporal distribution of solar radiation [12]. In particular, geostationary satellites provide information with high spatial and temporal resolution about the Earth's atmosphere and cloud cover over a large area [11].

However, the amount of solar energy incident on the ground strongly depends on the sky condition. Larger amounts of radiation are received at ground level when the sky is free of clouds. Moreover, when clouds are present, incident radiation depends on cloud type. This being so, most of the solar insolation algorithm models (e.g., Festa and Ratto [13] and Badescu [14]) consider the state of the sky [15]. The amount of cloud in the same time zone differs regionally, and due to the recent climate change, the incidence of clouds is changing regionally. Therefore, the importance of satellites, which can observe the characteristics of these complex clouds in real time, has been emphasized. Recent studies integrating a physical model and geostationary data showed reasonable results when compared with ground station measurements and revealed high temporally and spatially insolation [16, 17]. However, the problems of existing studies are that they did not take topography elements, such as slope and aspect, into consideration. It is important to consider topographic effects when calculating the amount of solar radiation because the amount of solar radiation actually arriving at a particular point is called global (or total) solar radiation and depends mainly on cloudiness, time of year, latitude, and surface geometry [18].

In this study, solar radiation received in slopes maps was created using the Communication, Ocean, and Meteorological Satellite (COMS) data and calculated based on a physical model. Additionally, to reflect actual surface geometry topographic information was also considered for the efficiency of solar insolation on the Korean peninsula. An accurate solar radiation from satellite would be helpful for estimating solar energy resource maps and deciding the location of solar energy facilities and would enable analysis of suitable land to supply energy to poor areas where electrical equipment is insufficient.

\section{Materials and Methods}

2.1. Data Used. COMS is the Republic of Korea's first geostationary orbit composite satellite to perform the duties of ocean and meteorological observation and communication services. This satellite provides observation of the Korean Peninsula and the larger Asia Pacific region at up to $8 \mathrm{~min}$
TABLE 1: Detailed COMS MI sensor specifications for mapping solar energy resources.

\begin{tabular}{lcc}
\hline $\begin{array}{l}\text { COMS MI } \\
\text { channel }\end{array}$ & Wavelength $(\mathrm{nm})$ & $\begin{array}{c}\text { Spatial resolution } \\
(\mathrm{km})\end{array}$ \\
\hline Visible & $550-800$ & $1 \times 1$ \\
Infrared 1 & $10,300-11,300$ & $4 \times 4$ \\
Infrared 2 & $11,500-12,500$ & $4 \times 4$ \\
Water vapor & $6,500-7,000$ & $4 \times 4$ \\
$\begin{array}{l}\text { Shortwave } \\
\text { infrared }\end{array}$ & $3,500-4,000$ & $4 \times 4$ \\
\hline
\end{tabular}

TABLE 2: Detailed specifications of the CM 21 pyranometer according to the ISO 9060 listing.

\begin{tabular}{lc}
\hline CM 21 pyranometer & Specifications \\
\hline Spectral range & $305-2,800 \mathrm{~nm}$ \\
Sensitivity & Between 7 and $17 \mu \mathrm{V} / \mathrm{Wm}^{-2}$ \\
Nonlinearity & $< \pm 0.2 \%\left(<1000 \mathrm{Wm}^{-2}\right)$ \\
Directional error & $< \pm 10 \mathrm{Wm}^{-2}$ \\
Tilt error & $< \pm 0.2 \%\left(\right.$ beam $\left.1000 \mathrm{Wm}^{-2}\right)$ \\
Operating temperature & $-40^{\circ} \mathrm{C}$ to $+80^{\circ} \mathrm{C}$ \\
Viewing angle & $2 \pi \mathrm{sr}$ \\
\hline
\end{tabular}

intervals for $24 \mathrm{~h}$ and is a significant contributor to weather forecasts and early warnings of high-impact weather events, such as typhoons and torrential rains. The COMS Meteorological Imager (MI) observes one visible band and four infrared bands. Its spatial resolution is $1 \times 1 \mathrm{~km}$ for the visible area, and it obtains infrared information from a 4 $\times 4 \mathrm{~km}$ area per pixel (Table 1 ). The data used were from 1 January 2012 to 31 December 2012 over the Korean peninsula. The study area was defined as the southern parts of the Korean peninsula from $34.00^{\circ} \mathrm{N}$ to $38.41^{\circ} \mathrm{N}$ and $125.36^{\circ} \mathrm{E}$ to $129.77^{\circ} \mathrm{E}$ with a $1 \mathrm{~km}$ spatial resolution using the UTM (Universal Transverse Mercator) World Geodetic System (WGS) 84. For physical observations made from the COMS satellite, we used the digital number (DN) to radiance and $\mathrm{DN}$ to brightness temperature conversion tables from the National Meteorological Satellite Center, Korea Meteorological Agency (http://nmsc.kma.go.kr/).

In this study, 37 ground station pyranometers of the CM21 model produced by Kipp and Zonen, established in the Korean peninsula, were used as validation data for accuracy assessment of satellite-based insolation (Figure 1). A detailed specification of the CM21 pyranometer, including its associated uncertainties, is presented in Table 2 [19].

The pyranometer data distributed by the Korea Meteorological Agency (KMA) provided hourly measurements based on an upper-hemisphere observation system.

In this study, to consider topography effects, the Global Land One-Kilometer Base Elevation (GLOBE) was used, which is an internationally designed, developed, and independently peer-reviewed global elevation model (DEM), with a latitude-longitude grid spacing of 30 arc-seconds [20]. Figure 2(a) shows GLOBE images over the study area, geometrically resampled to match the defined projection. It 


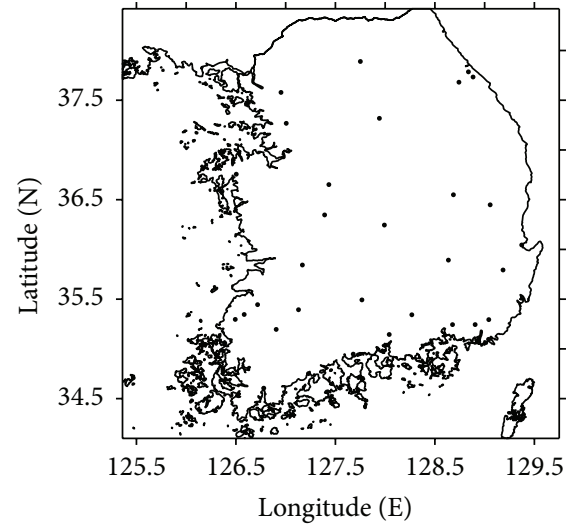

FIgURE 1: The location of each study area.

shows that the mountain range stretches from the northeast to the south of the Korean peninsula. Based on the DEM of GLOBE, the corresponding slope and aspect were retrieved by using the Environment for Visualizing Images (ENVI) version 5.0 topographic modeling function (Figures 2(b)-2(c)).

\subsection{Insolation from a Physical Model with Topography.} In contrast to previous empirical models, satellite-based physical insolation models utilize instantaneous satellite observation and atmospheric information [21]. To simplify the estimation of solar radiation using satellite data, we assumed that the hemispherical angular integral of the incident solar radiation consisted mainly of the direct solar radiation and diffuse radiation attenuated by the atmosphere. In other words, we did not consider the radiation effects of atmospheric constituents and cloud from hemispherical sphere due to the complicated physical characteristics and time-consuming calculations involved. Instead, for simplification, we adopted a pixel-based physical model to estimate the solar radiation. Considering the topographical effects of solar radiation, satellite-based incident radiation on a topographically effective pixel was also used to estimate the solar radiation received by slopes corresponding to the slope and aspect pixel values.

Atmospheric constituents such as Rayleigh scattering, aerosols, water vapor, and total ozone are used as input parameters to simulate the atmospheric effects due to absorption, scattering, and reflection. When simulating the satellitebased physical insolation with COMS MI data, we separated the atmospheric constituent products as input for the physical model since the improved atmospheric parameter could easily be replaced to obtain better results with the development of satellite sensors and ancillary data. COMS MI observation is mainly used for interpreting the effects of attenuation by cloud. Cloud is the main obstacle to acquiring reliable incident solar radiation on the surface, due to the high sensitivity of its temporal and spatial variations.

The suggested satellite-based insolation is based on the Kawamura physical model [21] and we improved its cloud factor by considering the satellite visible reflectance and solar zenith angle instead of using brightness temperature, because the pass depth of cloud is more sensitive to the amount of irradiance attenuation [22]. When determining the satellitebased insolation physical model over the study area, we placed a high priority on product consecution by using different satellites. The algorithms for solar insolation obtained with the geostationary satellites GMS-5 [21], MTSAT-1R [16], and COMS MI [23] were based on the Kawamura physical model and improved according to the characteristics of the onboard sensors. In this study, for consecution of the insolation over the study area, the Kawamura physical model was used. The details of the physical model are as follows $[16,17,21-25]$ :

$$
\begin{aligned}
S_{T 0} & =S_{I 0}+S_{D 0}, \\
S_{I 0} & =S\left(\tau_{O} \tau_{R}-\alpha_{W}\right) \tau_{A}, \\
S_{R} & =S \tau_{O}\left(0.5\left(1-\tau_{R}\right)\right) \tau_{A}, \\
S_{A} & =S\left(\tau_{O} \tau_{R}-\alpha_{W}\right) F_{C} \omega_{O}\left(1-\tau_{A}\right), \\
S_{D 0} & =\left(S_{R}+S_{A}\right), \\
S & =I\left(\frac{d_{M}}{d}\right)^{2} \cos \theta,
\end{aligned}
$$

where $S_{T 0}, S_{I 0}, S_{R}$, and $S_{A}$ are the total insolation, direct irradiance, diffuse irradiance due to Rayleigh scattering, and diffuse irradiance due to scattering by aerosols, respectively. Detailed descriptions of the parameters used for the physical model of satellite-based insolation are presented in Table 3 [22].

When estimating insolation with satellite data, atmospheric variables are crucial parameters, the validity of which will determine the accuracy of the final products. We studied the variations in attenuation by atmospheric constituents such as ozone, aerosol, water vapor, and cloud. Before considering atmospheric attenuation along each of these parameters, the relative air mass was estimated (Table 3 ). Relative air mass is used in most atmospheric parameterization equations, because the level of attenuation due to existing constituents (ozone, aerosols, Rayleigh scattering, and water vapor) strongly depends on the relative optical depth determined by the sensor-target-solar geometry [22]. In the case of transmittance due to absorption by ozone, the following equation is used:

$$
\begin{aligned}
\tau_{O}= & 1-\frac{0.02118(U m)}{\left(1+0.042(U m)+3.23 \times 10^{-4}(U m)^{2}\right)} \\
& +\frac{1.082 U}{(1+138.6(U m))^{0.805}}-\frac{0.0658(U m)}{\left(1+(103.6(U m))^{3}\right)},
\end{aligned}
$$

where $\tau_{O}$ is the transmittance due to absorption by ozone, $U$ is the amount of ozone, and $m$ is relative air mass. The total ozone amount is derived from Ozone Monitoring Instrument (OMI)/Total Ozone Measurement Satellite (TOMS) data from the Earth Observing System Data and Information System, in the Distributed Active Archive Center at the Goddard Space Flight Center. In this study, the daily total 


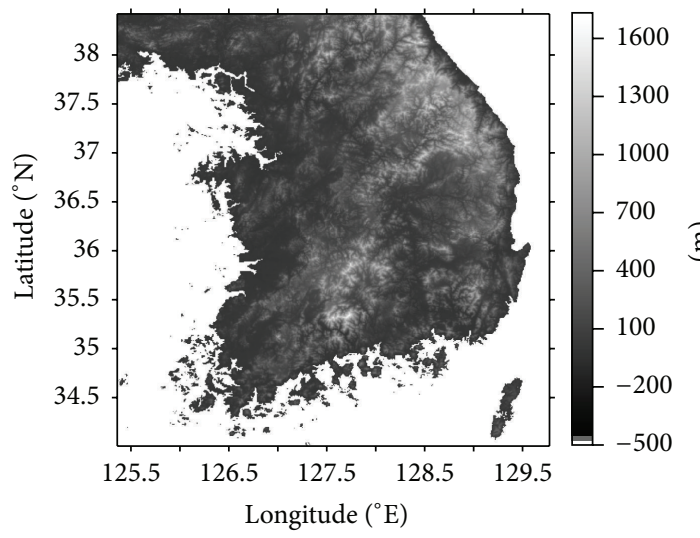

(a)

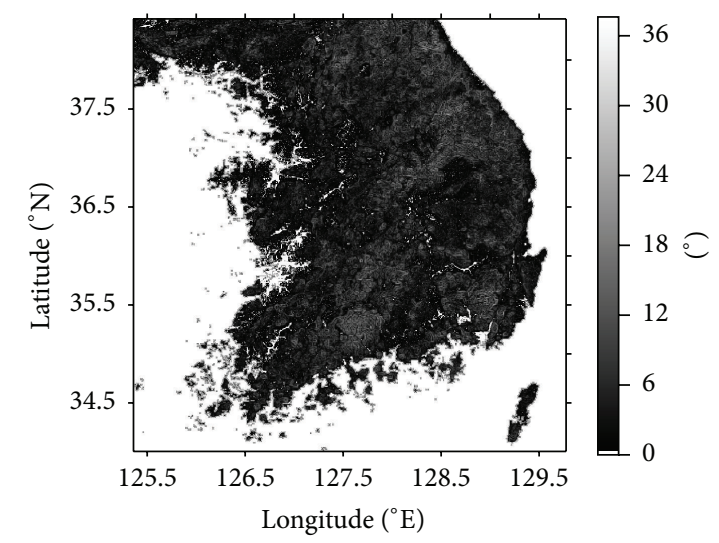

(b)

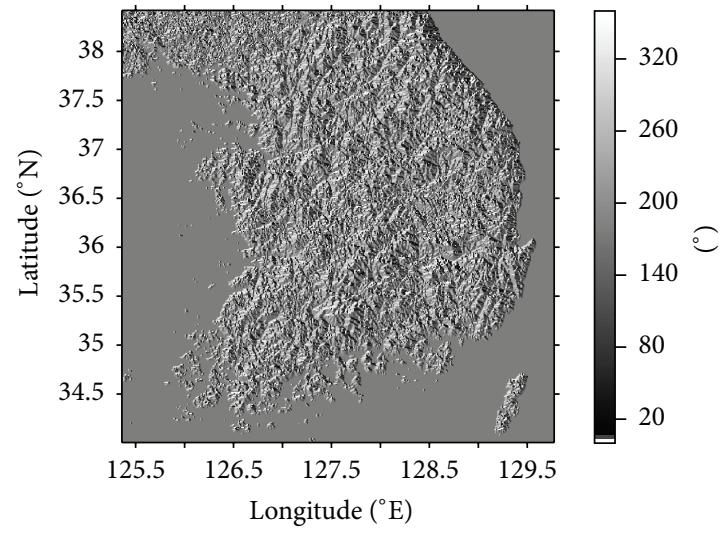

(c)

FIGURE 2: Topography datasets from GLOBE DEM data with $1 \mathrm{~km}$ spatial resolution. (a) DEM and ((b) and (c)) slope and aspect, respectively.

TABLE 3: Description of parameters used for estimation of satellite-based insolation.

\begin{tabular}{|c|c|c|}
\hline & Parameter & Reference \\
\hline$d$ & Sun-earth distance & \\
\hline$d_{M}$ & Sun-earth distance (annual mean) & \\
\hline$F_{C}$ & Ratio of forward to total scattering by aerosols & Robinson [35] \\
\hline I & Solar constant & Frohlich and Wehrli [36] \\
\hline$S$ & Incident solar constant & \\
\hline$S_{T 0}$ & Total insolation & \\
\hline$S_{T}$ & Topographically corrected total insolation & \\
\hline$S_{D 0}$ & Diffuse irradiance & \\
\hline$S_{D}$ & Topographically corrected diffuse irradiance & \\
\hline$S_{A}$ & Diffuse irradiance due to scattering by aerosols & Paltridge and Platt [37] \\
\hline$S_{I 0}$ & Direct irradiance & Paltridge and Platt [37] \\
\hline$S_{I}$ & Topographically corrected direct irradiance & \\
\hline$S_{R}$ & Diffuse irradiance due to Rayleigh scattering & Paltridge and Platt [37] \\
\hline$\alpha_{W}$ & Absorption of water vapor & Lacis and Hansen [28] \\
\hline$\theta$ & Solar zenith angle & \\
\hline$\phi$ & Solar azimuth angle & \\
\hline$\tau_{A}$ & Transmittance due to attenuation by aerosols & Frouin et al. [27] \\
\hline$\tau_{O}$ & Transmittance due to absorption by ozone & Lacis and Hansen [28] \\
\hline$\tau_{R}$ & Transmittance due to Rayleigh scattering & Kizu [26] \\
\hline$\omega_{\mathrm{O}}$ & Single scattering albedo & \\
\hline
\end{tabular}


TABLE 4: The determined cloud LUT for solar radiation with COMS MI [22].

\begin{tabular}{|c|c|c|c|c|c|c|c|c|c|c|}
\hline \multirow{2}{*}{$\operatorname{SZA}\left({ }^{\circ}\right)$} & \multicolumn{10}{|c|}{ Cloud reflectance } \\
\hline & 0.1 & 0.2 & 0.3 & 0.4 & 0.5 & 0.6 & 0.7 & 0.8 & 0.9 & 1.0 \\
\hline 10 & 0.88 & 0.81 & 0.70 & 0.58 & 0.47 & 0.35 & 0.23 & 0.12 & 0.02 & 0.01 \\
\hline 20 & 0.88 & 0.81 & 0.69 & 0.57 & 0.45 & 0.33 & 0.21 & 0.02 & 0.013 & 0.01 \\
\hline 30 & 0.88 & 0.80 & 0.67 & 0.54 & 0.42 & 0.29 & 0.16 & 0.04 & 0.01 & 0.01 \\
\hline 40 & 0.88 & 0.78 & 0.64 & 0.50 & 0.35 & 0.21 & 0.07 & 0.01 & 0.01 & 0.01 \\
\hline 50 & 0.87 & 0.75 & 0.58 & 0.42 & 0.25 & 0.09 & 0.01 & 0.01 & 0.01 & 0.01 \\
\hline 60 & 0.86 & 0.69 & 0.49 & 0.28 & 0.09 & 0.01 & 0.01 & 0.01 & 0.01 & 0.01 \\
\hline 70 & 0.83 & 0.58 & 0.29 & 0.07 & 0.01 & 0.01 & 0.01 & 0.01 & 0.01 & 0.01 \\
\hline 80 & 0.74 & 0.29 & 0.03 & 0.01 & 0.01 & 0.01 & 0.01 & 0.01 & 0.01 & 0.01 \\
\hline
\end{tabular}

ozone amount was used because the sensitivity of SSI to the total quantity of ozone is low, especially when the solar zenith angle is high $[16,26]$.

For the transmittance due to attenuation by aerosols, the method developed in Frouin et al. [27] was used:

$$
\tau_{A}=\exp \left(\frac{-(0.066+0.704 / V)}{\cos \theta}\right)
$$

where $V$ is visibility. In this study, we used Moderate Resolution Imaging Spectroradiometer (MODIS) aerosol optical depth (AOD) products for inputting the visibility by resampling its coarse $10 \mathrm{~km}$ spatial resolution for the corresponding projection. When no MODIS products were available, visibility was kept at a fixed value of $20 \mathrm{~km}$ indicating nominal weather conditions in South Korea.

In the case of water vapor absorption, the absorptance of water vapor, $\alpha_{W}$, was estimated using precipitable water, $W$, which is derived using COMS MI infrared bands. To calculate absorptance, we use the equations from Lacis and Hansen [28] and Chesters et al. [29]:

$$
\begin{aligned}
\alpha_{W} & =\frac{2.9 W m}{\left((1+141.5 W m)^{0.635}+5.925 W m\right)}, \\
W & =\left(\frac{1}{0.095}\right)\left[\left(\frac{1}{\sec \theta}\right) \ln \left[\frac{\left(T_{1}-T_{a}\right)}{\left(T_{2}-T_{a}\right)}\right]-0.0025\right],
\end{aligned}
$$

where $\alpha_{W}$ and $W$ are the absorptances of water vapor and precipitable water, respectively. $T_{1}$ is brightness temperature of COMS MI at $10.2 \mu \mathrm{m}$, and $T_{2}$ is brightness temperature of COMS MI at $12.5 \mu \mathrm{m}$. $T_{a}$ is the air temperature, which is estimated as $T_{2}-2.2^{\circ}$ from Chesters et al. [29].

In this study, for actual solar energy resource mapping of the study area, topographic information was considered using GLOBE topography data. To apply topographic effects of the study areas to COMS-based insolation, the following equations were used [30-32]:

$$
\begin{aligned}
S_{I} & =S_{I 0}\left[\cos s \cos \theta+\sin s \sin \theta \cos \left(\phi-A_{s}\right)\right], \\
S_{D} & =S_{D 0}(\cos )^{2}\left(\frac{s}{2}\right),
\end{aligned}
$$

where $s$ and $A_{s}$ are the slope angle and azimuth of slope, respectively. For direct irradiance, (5) was applied to consider the effect of slope and aspect. For diffuse irradiance on slope, assuming isotropic sky radiation, diffuse insolation was retrieved using (6). The process of physical modeling involved mainly separating images according to cloudinesscorresponding pixels. In the case of clear sky conditions in (7), total insolation, which consists of $S_{I}$ and $S_{D}$, was used as the final insolation product. In cloudy conditions, cloud factor was applied to total insolation using (8):

$$
\begin{aligned}
& S_{T}=S_{I}+S_{D} \quad \text { (clear conditions) }, \\
& S_{T}=\left(S_{I}+S_{D}\right) \times \text { Cloud Factor }
\end{aligned}
$$

$$
\text { (cloudy conditions), }
$$

where cloud factor is the ratio of attenuation by cloud for incident solar radiation using COMS visible band and solar zenith angle [22]. The COMS visible band was used to indirectly determine the thickness of the target clouds, where a higher cloud reflectance indicates a lower cloud penetration value. Additionally, the solar zenith angle over the cloudy area is used to determine cloud effects, because the attenuation of incident solar radiation by clouds depends on the pass depth of the clouds [16]. To determine the cloud factor, reference match-up datasets between satellite observations (top of the atmosphere reflectance and solar zenith angle) and cloudy pyranometer measurements were first analyzed and the cloud attenuation was estimated as a function of cloudy reflectance and solar zenith angle by using a simple look-up table [22]. Table 4 shows the simplified cloud LUT for solar radiation with COMS MI.

\section{Results}

To compare satellite-based insolation with ground stationbased pyranometer, temporally and spatially systematic differences were considered to match up datasets. From the point of view of temporal discrepancy, satellite-based insolation was estimated by using instantaneous observed images, while incident irradiances observed by pyranometer measurements every 2 min were integrated to estimate an hourly based ground measurement. By adjusting the hour factor in the physical model, the temporal discrepancy was reduced when establishing matched-up data [33]. For spatial discrepancies induced by systematic differences between pixelbased satellite insolation and hemisphere upward-looking 
based pyranometer measurement, a representative test on the pyranometer measurement of insolation through satellite observation was performed to determine the spatial representativeness of the ground stations. In this study, we averaged the satellite-based insolation using windows of sizes $1 \times 1,3$ $\times 3$, and $5 \times 5$ by comparing the calculated insolation values with pyranometer measurements for both clear and cloudy sky conditions. The results of the comparison are shown in Figure 3. By using averaged values for each window size, we mitigated the effects of possible cloud drift between adjacent pixels during the hour-long averaging interval [34]. In Figure 3, scatterplots show comparisons of the satellite-based measurements of insolation with ground measurements for window sizes from $1 \times 1$ to $5 \times 5$ for clear (a, c, e) and cloudy (b, d, f) conditions. The relationship between satellite-based measurements of insolation and pyranometer measurement appears to be linear, with most of the data points located close to the reference line $(R=1.0)$, though many data points deviate significantly from this line. In the case of the clear sky conditions shown in the (a, c, e) plots of Figure 3 , the estimated satellite-based insolation was more accurate than it was for cloudy conditions because we did not have to take the effects of clouds into account. The statistical values were also more accurate in this case, as the window size increased; we obtained a root mean square error (RMSE) value of $72.49 \mathrm{~W} / \mathrm{m}^{2}$, a mean bias error (MBE) of $6.64 \mathrm{~W} / \mathrm{m}^{2}$, and a value for $R^{2}$ (determination coefficients) of 0.903 . Since the effect of cloud is to attenuate incident solar radiation, black dots show areas of low insolation under cloudy conditions (b, $\mathrm{d}, \mathrm{f}$ ). The statistical values for the RMSE, MBE, and $R^{2}$ decreased to $106.94 \mathrm{~W} / \mathrm{m}^{2},-4.99 \mathrm{~W} / \mathrm{m}^{2}$, and 0.712 , respectively. Generally, as collocated window sizes increased, RMSE and $\mathrm{MBE}$ decreased for both sky conditions. As window sizes increased beyond $3 \times 3$, the accuracy of satellite-based insolation values stabilized. Therefore, in this study, $5 \times 5$ widow sizes were determined to be adequately representative of the ground stations. Based on the comparisons with the pyranometer, an accuracy assessment for the physical model with COMS MI images was performed and showed reliable accuracy for mapping of solar energy resources over the study area. In this study, we did not compare topographically corrected satellite-based insolation with pyranometer data for accuracy assessment, because all of the pyranometer instruments were carefully installed on a horizontal plane, indicating that they did not reflect the topography effect. That is to say, most of the measurement sites were established based on World Meteorological Organization (WMO) criteria (Guide to Meteorological Instruments and Methods of Observation WMO-No. 8), which meets requirements for reducing adjacent effects.

Before analyzing the spatial characteristics of the estimated insolation, we estimated the sensitivity of the results to variation in the values for water vapor, visibility, and total ozone input as atmospheric variables into the physical model. Figure 4 shows contour diagrams of the satellite-based insolation as a function of water vapor, visibility, and total ozone. As shown in Figure 4(a), when comparing water vapor with visibility, insolation was more sensitive to water vapor levels. In the bottom contour diagram in Figure 4(a), the physical model was more sensitive to the water vapor content than visibility when the visibilities were greater than $10 \mathrm{~km}$. Ozone levels vary more than water vapor, but the model is less sensitive to ozone variation. When comparing visibility to ozone, visibility was the dominant factor, with the model indicating the highest sensitivity to visibilities of less than $10 \mathrm{~km}$. We concluded that the simulation model was most sensitive to water vapor, but visibility was also a significant consideration in the case of thick aerosol optical depth.

Lastly, we produced an integrated monthly and yearly solar radiation map from COMS hourly based insolation data for 2012 over the Korean peninsula. The original solar radiation monthly maps, without considering topography, are presented in Figure 5. As seen in the figures, temporal variations are well described, showing lower values (blue color) close to winter and higher insolation (red color) close to summer. Because integrating the physical model with the COMS MI image is designed to reflect the temporal variation of atmospheric conditions, especially for cloud, the detailed patterns of solar radiation map are well represented. For example, the solar radiance map for the south and east parts of the peninsula had lower values (yellow color) in June 2012 despite it being summer, which has the highest extra solar irradiance. In July, the solar radiance map shows a low value in the north (green color) and central (yellow color) areas. Those lower areas during the June and July period, compared with May, mainly originate from the rainy monsoon season, which is called Jang-Ma in the Republic of Korea. According to KMA weather reports (http://www.climate.go.kr/), Jang-Ma started on 18 June 2012 and lasted until 17 July 2012 and moved from south to north. This means that the regional atmospheric conditions, such as the movement of the seasonal rain front, are well captured in the solar energy resource map. Furthermore, spatial variations are also well visualized in the original solar radiance map. For the whole maps, because the high mountain range area has severe weather conditions, meaning a high rate of cloudiness, constantly low value areas are well matched to the high elevation of the mountain ranges. The northeast coast area, close to the highest mountain range stretching from north to south, has reverse solar radiance patterns between February and August. That abnormal pattern is inferred by the seasonal variation of foehn wind, a dry and hot downward wind that occurs on the leeside of a mountain range. The area opposite (upwind) to the mountain site of the foehn wind appears to be cloudy, which reduces insolation. Generally, since periodic winds blowing in February and August occur from opposite sides, the foehn wind shows similar seasonal variation. Therefore, in Figure 5, the solar radiance map of the northeast shows the opposite pattern for the mountain range between February and August.

The topographically corrected solar radiance maps are presented in Figure 6. The most effective influence on application of topography information on solar radiance maps is the detailed surface geometry of the terrain. In the case of the original solar energy resource maps in Figure 5, because their spatial resolution was $4 \mathrm{~km}$ from use of the COMS MI image a coarse spatial pattern is shown, while the topographically corrected solar radiance map with a $1 \mathrm{~km}$ resolution from the GLOBE DEM captures the detailed terrain effects and 


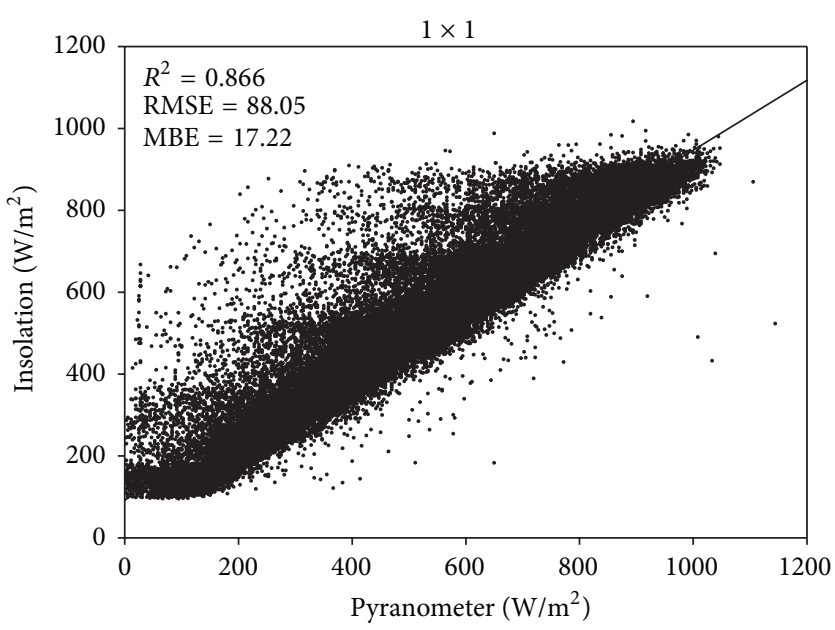

(a)

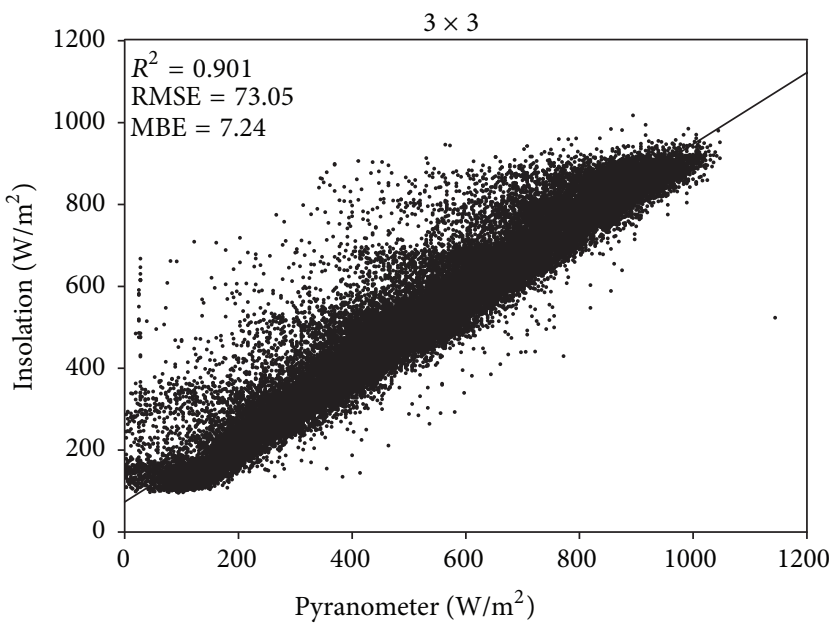

(c)

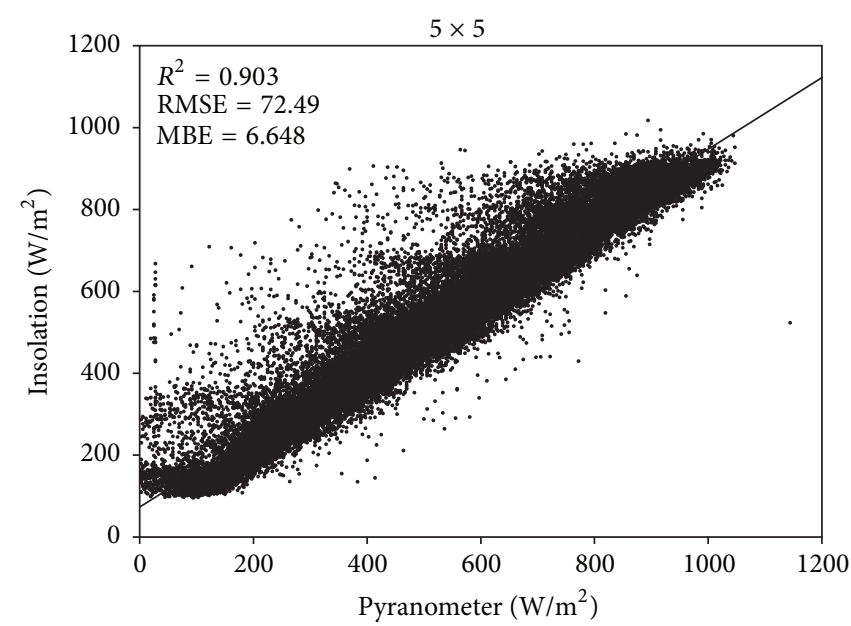

(e)

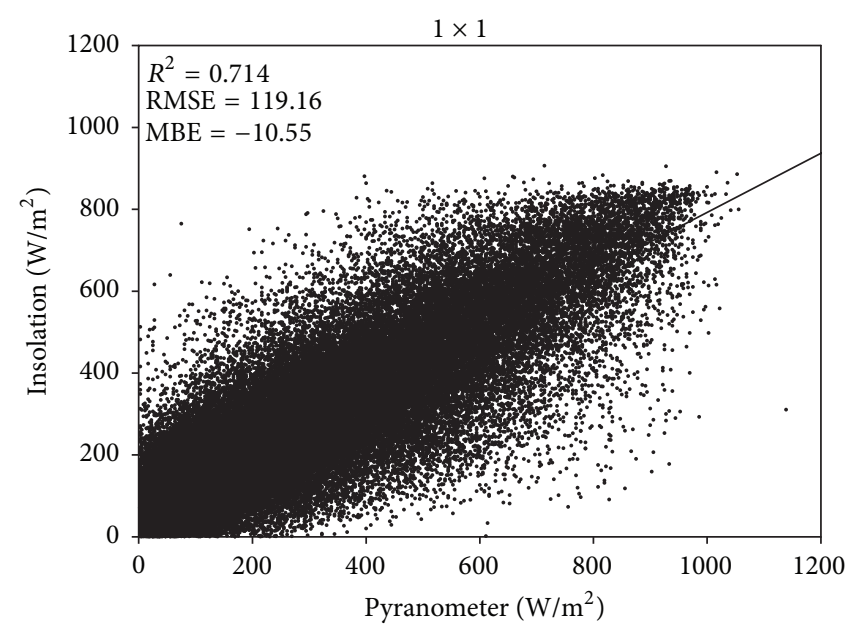

(b)

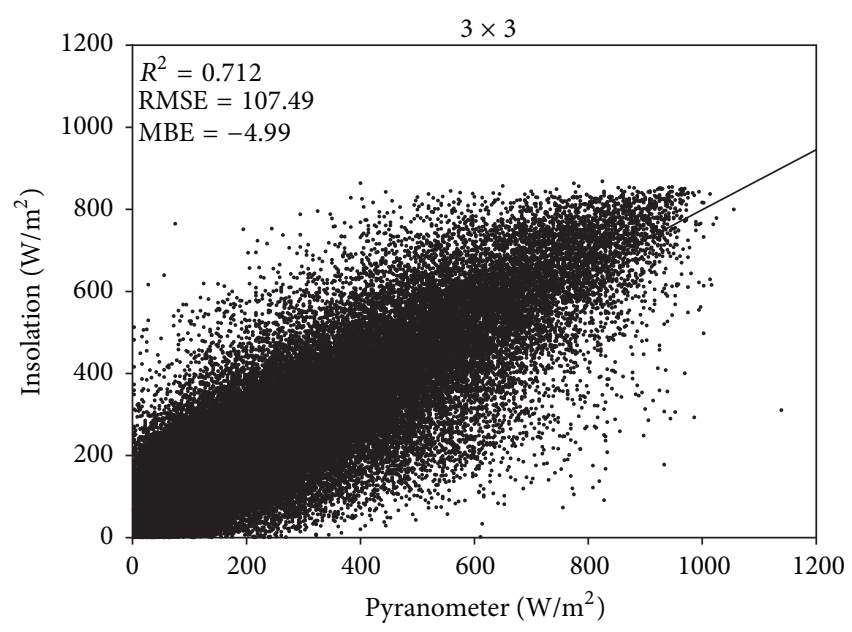

(d)

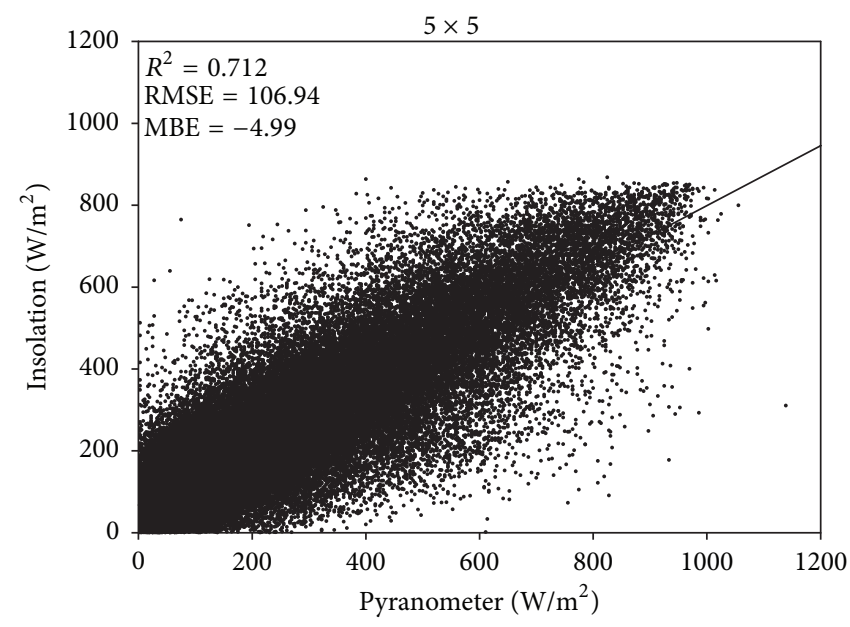

(f)

Figure 3: The scatterplots between satellite-based insolation and pyranometer data during 2012. Clear (a, c, e) and cloudy (b, d, f) sky conditions. 


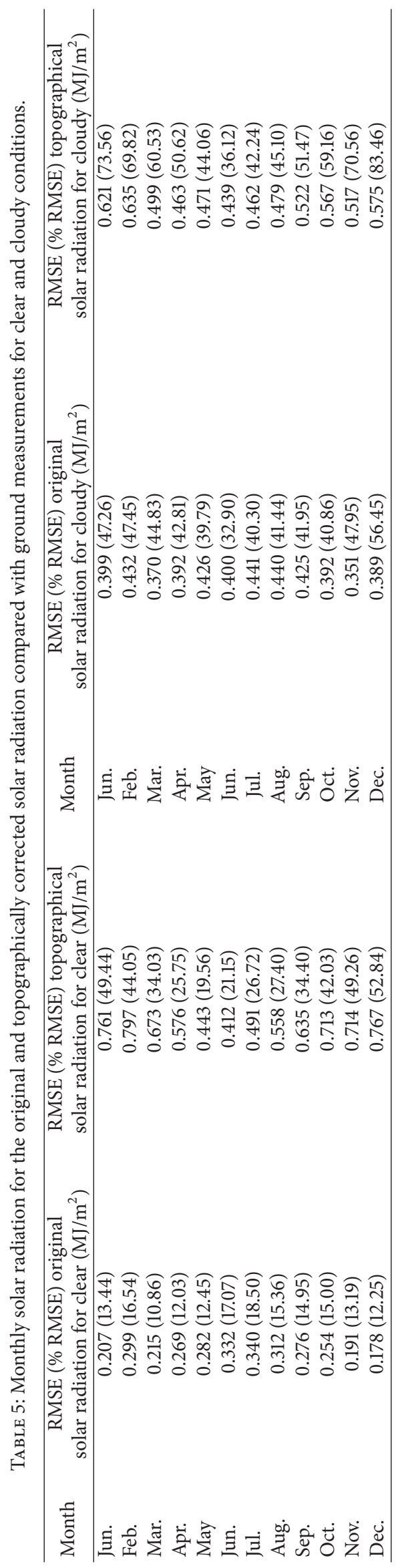




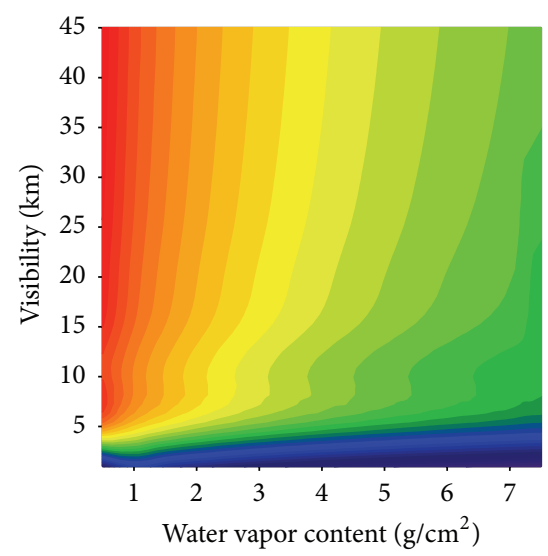

(a)
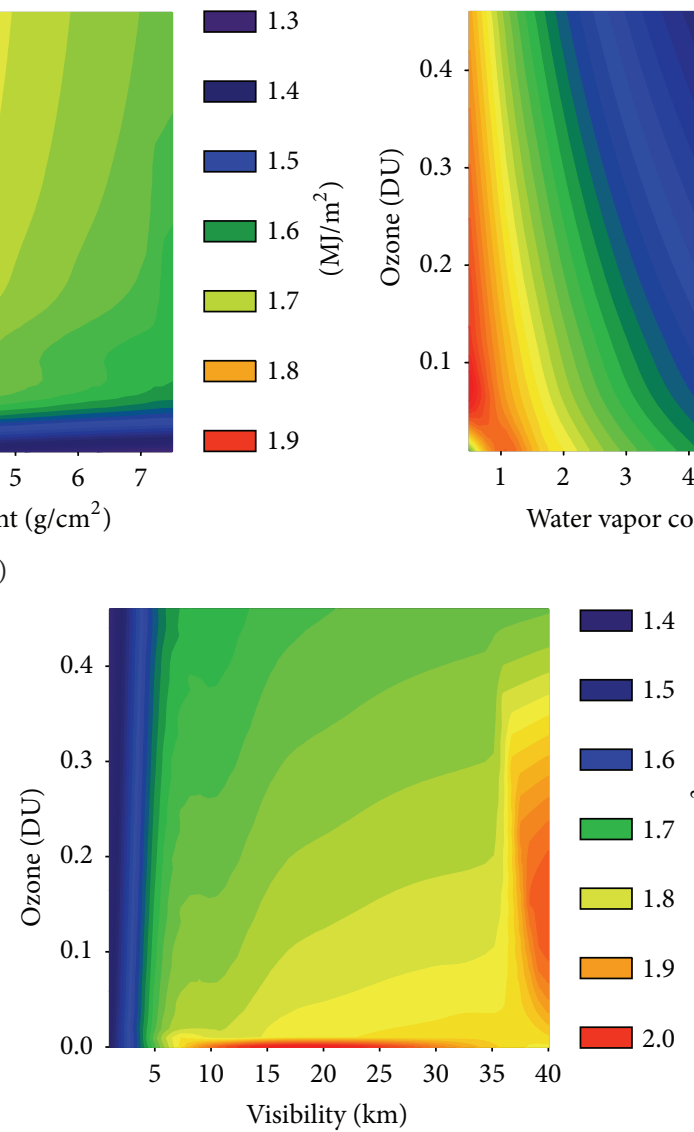

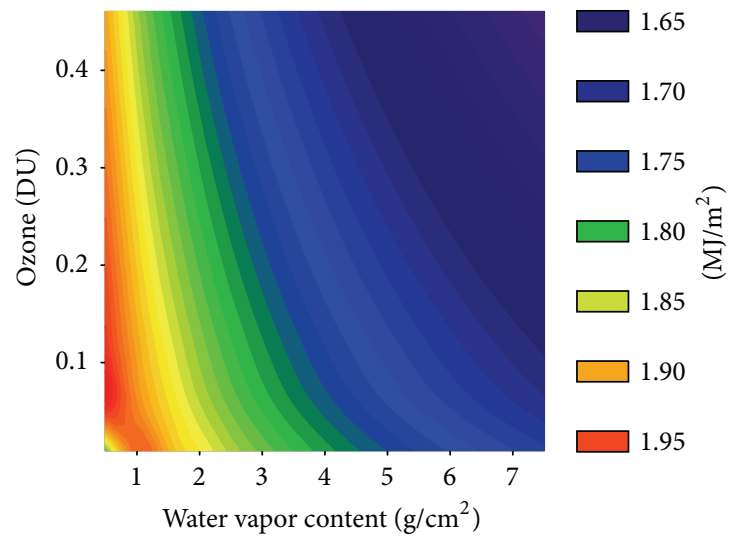

(b)

(c)

FIGURE 4: Contour diagrams of insolation as a function of water vapor, visibility, and total ozone based on the physical model. (a) Water vapor and visibility, (b) water vapor and ozone, and (c) visibility and ozone.

resembles a high resolution map. The overall temporal characteristics of topographically corrected solar energy resource maps tend to not only show the similar temporal pattern of the original solar radiance maps but also well describe the topography of the study area under benign weather conditions. For example, the topographically corrected solar energy resource map shows a better result with regard to the spatial characteristics of foehn wind, showing more detailed reverse patterns in the northeast part of the mountain range. However, the topographically corrected solar radiance map taken in the summer season indicates reduced insolation induced by the rainy monsoon, which can be found as coarse spatial resolution similar to the original map. In other words, the detailed surface geometry of the topographically corrected solar radiance is faint during the summer monsoon season. This happens because cloud diffuses incident solar radiation, which contributes overall to the reduction of the topographical effect in our physical model.

Table 5 compares the monthly ground measurements with the original and topographically corrected COMS MIbased solar radiation for clear and cloudy conditions. According to the results from Table 5, the monthly solar radiation for the clear sky condition was more accurate than for cloudy conditions, similar to previous scatterplot results. In terms of the seasonal variation in the model accuracy, summer, which is the season with the highest rate of cloudy conditions, has the lowest accuracy with a $0.340 \mathrm{MJ} / \mathrm{m}^{2}$ RMSE in July. The seasonal accuracy of solar radiation under cloudy conditions was similar, with a high RMSE during summer. The original solar radiation from COMS MI seemed to be more accurate than the topographically corrected solar radiation since most of the selected manned ground measurement sites were established based on WMO criteria. That is to say, pyranometer measurements did not reflect the topographical effects for each selected ground site.

In this study, we also produced yearly solar radiation maps for the study area. As seen in Figure 7, the most outstanding difference between the original and topographically corrected solar radiation maps was the spatial pattern we expected. Similar to the monthly map, DEM was an effective parameter in terms of determining the value of insolation. Although the original solar radiation map did not consider topography, the location of mountains having severe weather conditions could have been included (Figure 7(a)). Therefore, we can conclude that the topographically corrected solar radiation map not only reflects the temporal variations of regional atmospheric conditions but also considers the topographical effect. Based on the suggested solar maps, we 

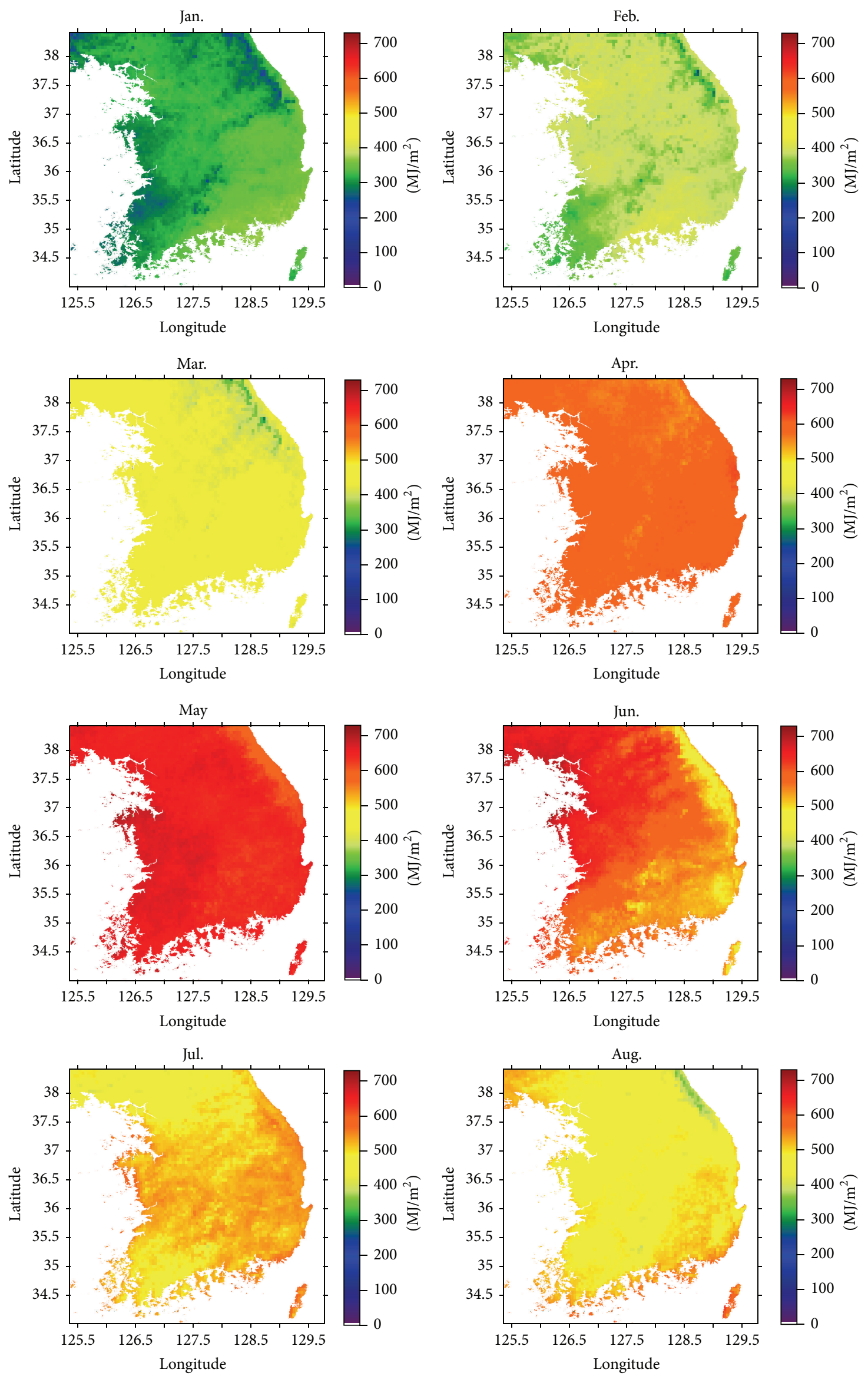

Figure 5: Continued. 

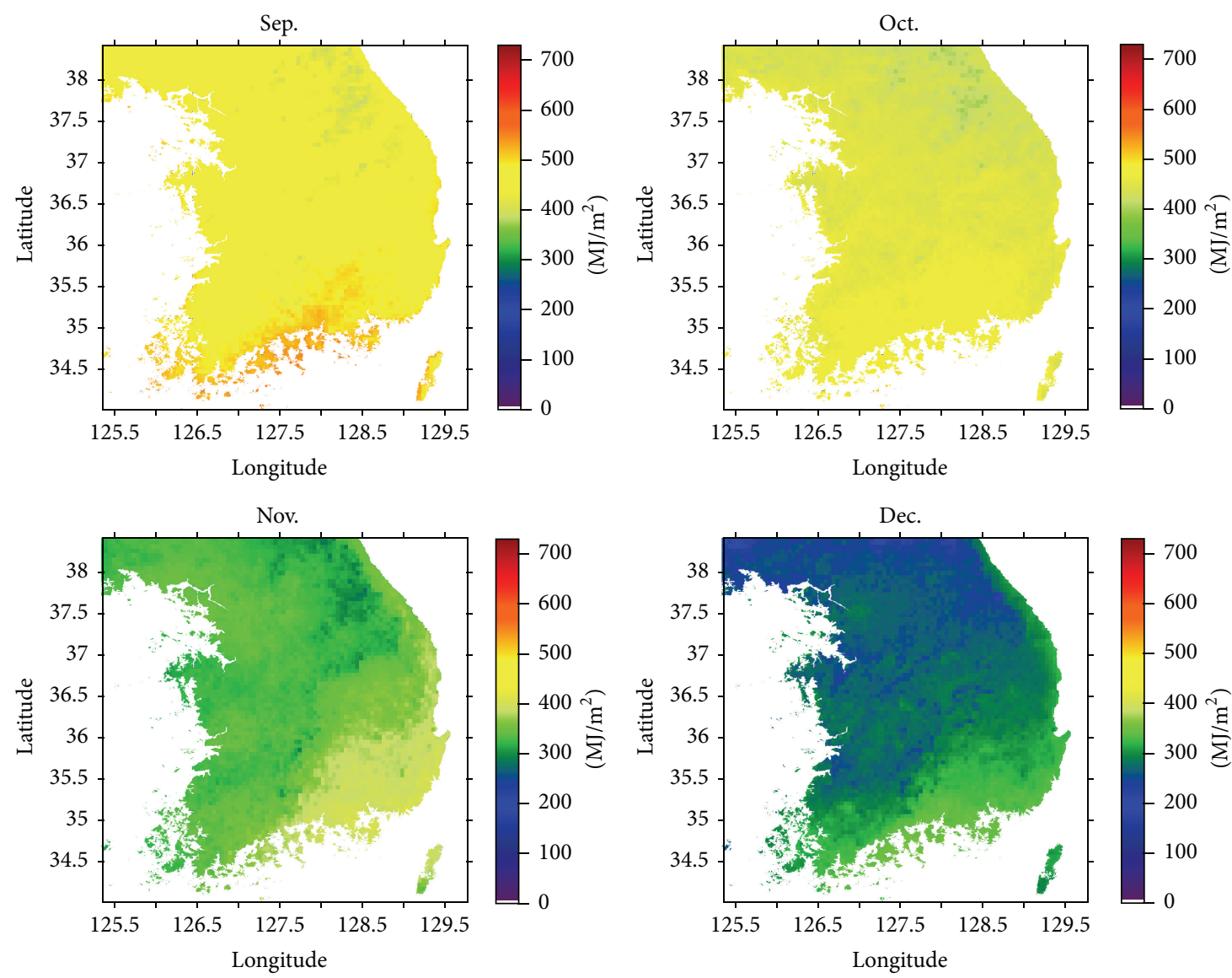

FIGURE 5: Monthly original solar radiance map based on integrating the physical model with satellite data over the study area.

can determine the most efficient areas for solar resources in the Korean peninsula; some parts of the western and southeastern regions (shown as blue rectangles in Figure 7(b)) are considered the most efficient solar energy resource area.

\section{Summary and Conclusions}

In this study, solar radiation received in slopes maps, based on integrating a physical model with COMS MI images, were estimated by additionally considering topography from GLOBE DEM during 2012 for the Republic of Korea. Before presenting a solar radiation map, we assessed the accuracy of the results compared with measurements from 37 ground stations. The temporal and spatial system differences between satellite sensor and pyranometers were carefully considered and showed reasonable accuracy for clear and cloudy sky conditions. In the case of clear sky conditions, a benign weather condition, the model was more accurate than it was in the case of cloudy conditions, yielding an RMSE of 106.94 W/m $/ \mathrm{m}^{2}$ and an MBE of $-4.99 \mathrm{~W} / \mathrm{m}^{2}$ for $3 \times 3$ window sizes. The RMSE and MBE in overcast conditions over $3 \times$ 3 windows were $72.49 \mathrm{~W} / \mathrm{m}^{2}$ and $6.64 \mathrm{~W} / \mathrm{m}^{2}$, respectively, indicating a greater reduction in accuracy than for clear conditions, but reasonable in comparison with previous studies $[27,31,32]$. Based on scatterplots for both sky conditions, we conclude that integrating a physical model with COMS MI image is a reliable method of mapping solar radiation without considering topography. Before analyzing the spatial characteristics of the estimated insolation, we analyzed the sensitivity of atmospheric constituents and showed that the simulation model was most sensitive to water vapor. In this study, topography from the $1 \mathrm{~km}$ GLOBE DEM was applied to the original solar radiation map, since the amount of solar radiation actually depends mainly on surface geometry [29]. Monthly and yearly original and topographically corrected solar radiation maps were estimated for 2012. In the case of the monthly maps, both original and corrected maps captured the temporal variations of regional atmospheric conditions such as the movement of rainy monsoon fronts. While, as we expected, the topographically corrected solar radiation map showed more detailed and sophisticated effects of the Korean surface geometry, indicating they could reflect more accurately the real surface terrain. However, during the summer season, which has a high rate of cloudiness, the topographically corrected solar radiation maps did not capture the surface geometry in the same way as the original maps, for two reasons. First, our suggested physical model was not designed to consider downward diffused radiance by cloud on surface geometry. Second, the physical characteristics of complex cloud diffusion are very difficult to parameterize. 

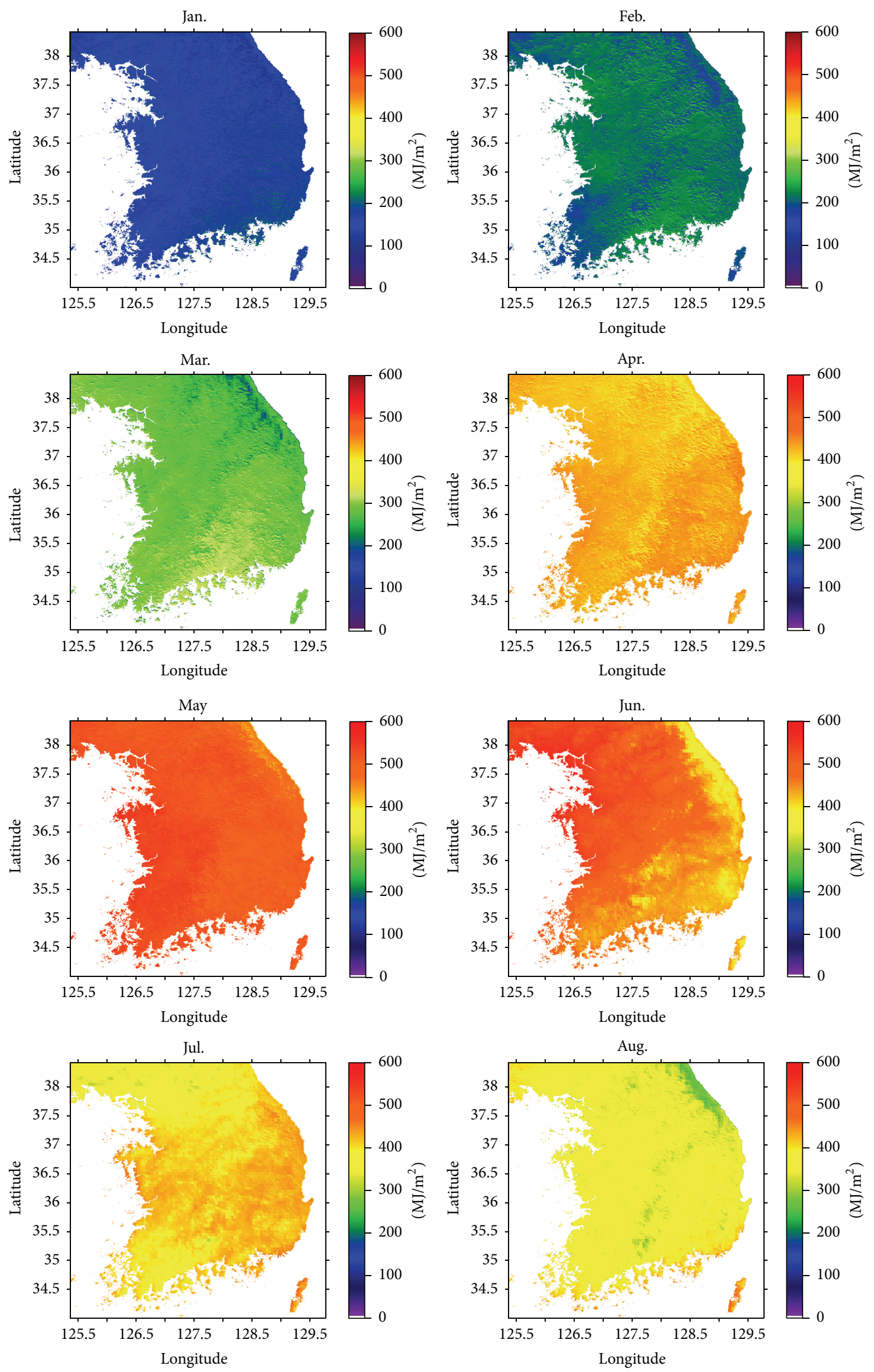

Figure 6: Continued. 

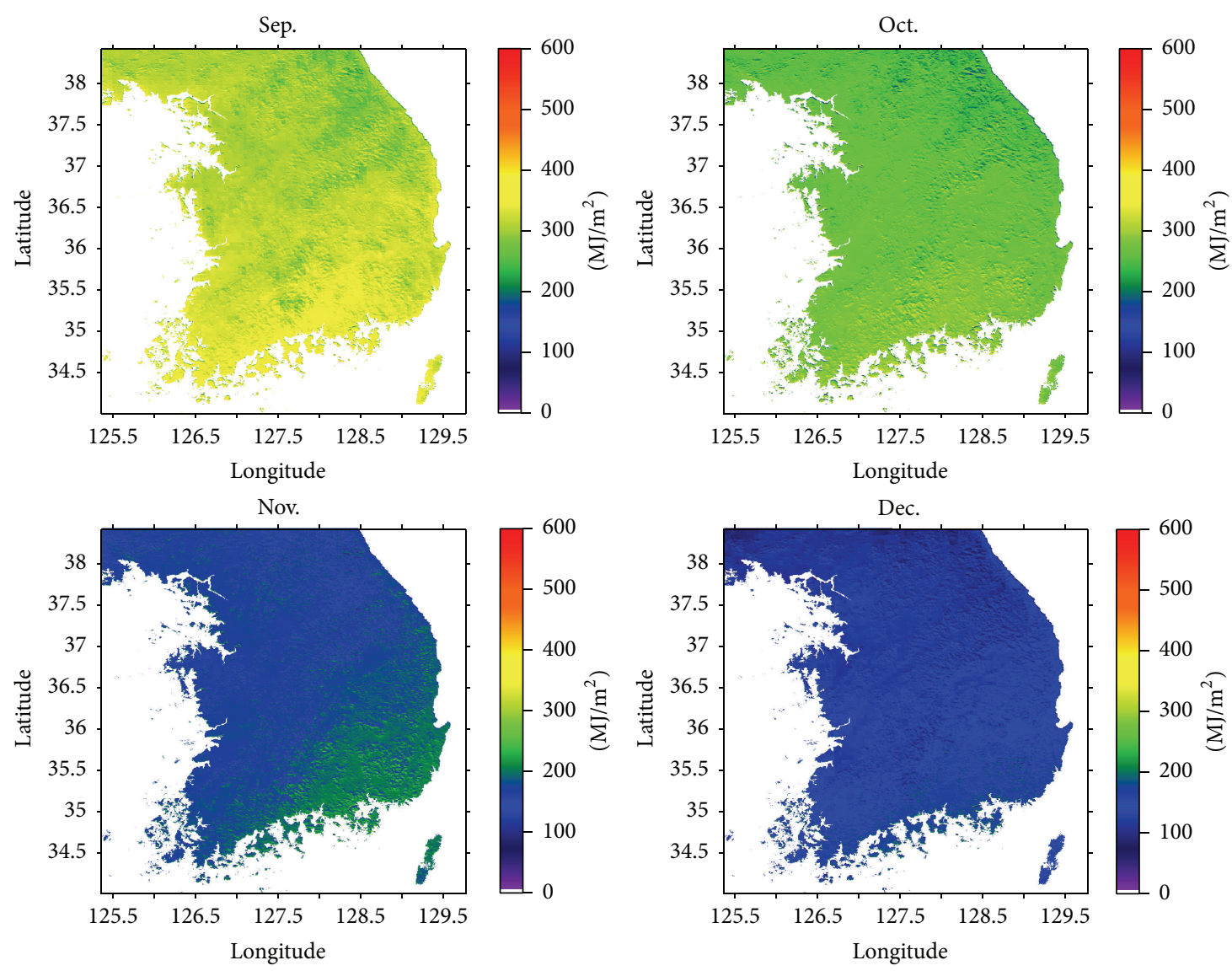

FIGURE 6: Monthly topographically corrected solar radiance map based on integration of the physical model with satellite data for the study area.

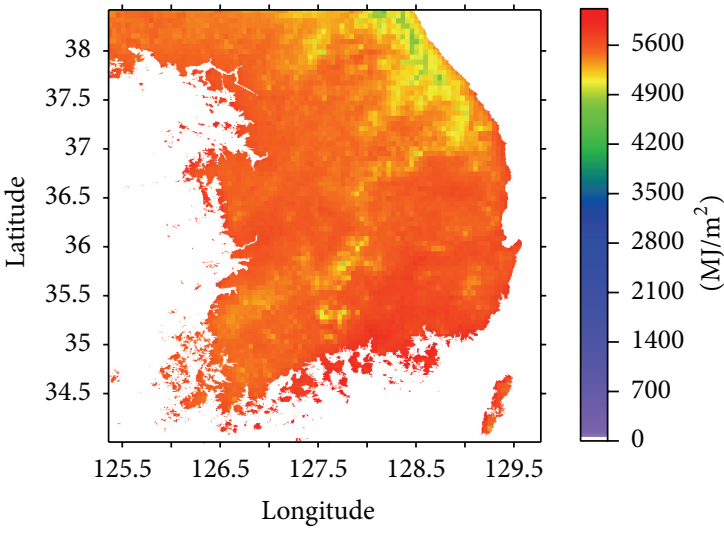

(a)

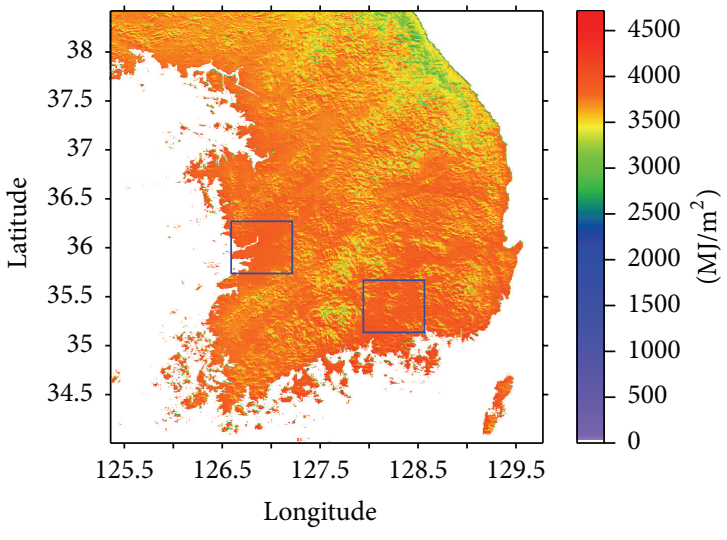

(b)

FIGURE 7: Yearly original (a) and topographically corrected (b) solar radiation map of the study area.

In addition, the monthly RMSEs of the original solar radiation seemed to have better accuracy when compared with the topographically corrected values for selected manned ground pyranometers. We inferred that horizontally deployed pyranometers that do not consider environmental topography do not provide good reference data for the data to not reflect the actual topographical effects of solar radiation received by slopes. Finally, the temporally and spatially different patterns found in the yearly solar radiation map are also present in the monthly map. We conclude that our final solar radiation map is useful for determining the areas of greatest solar energy resources, since it not only captures atmospheric variations but also reflects the surface geometry effects over the study domain.

In future works, for a more detailed solar radiation received in slopes map, we plan to perform further analysis 
by using GIS information based on our final solar energy resource map. To validate the topographically corrected insolation derived from satellite images, we plan to establish pyranometers which would enable us to determine the effects of regional variations in terrain. We plan to install pyranometers in mountainous areas and valleys, anticipating complicated topographical effects in such terrain. We also recognize the importance of solar radiation climatology and plan to study solar radiation climatology when sufficient COMS MI data are secured.

\section{Competing Interests}

The authors declare that there is no conflict of interests regarding the publication of this paper.

\section{Acknowledgments}

This work was funded by the Korea Meteorological Administration Research and Development Program under Grant KMIPA 2015-5040.

\section{References}

[1] O. Ellabban, H. Abu-Rub, and F. Blaabjerg, "Renewable energy resources: current status, future prospects and their enabling technology," Renewable and Sustainable Energy Reviews, vol. 39, pp. 748-764, 2014.

[2] S. M. Robaa, "Validation of the existing models for estimating global solar radiation over Egypt," Energy Conversion and Management, vol. 50, no. 1, pp. 184-193, 2009.

[3] K. Bakirci, "Models of solar radiation with hours of bright sunshine: a review," Renewable and Sustainable Energy Reviews, vol. 13, no. 9, pp. 2580-2588, 2009.

[4] Q. Dai and X. Fang, "A simple model to predict solar radiation under clear sky conditions," Advances in Space Research, vol. 53, no. 8, pp. 1239-1245, 2014.

[5] S. Janjai, P. Pankaew, J. Laksanaboonsong, and P. Kitichantaropas, "Estimation of solar radiation over Cambodia from long-term satellite data," Renewable Energy, vol. 36, no. 4, pp. 1214-1220, 2011.

[6] S. Janjai, "A method for estimating direct normal solar irradiation from satellite data for a tropical environment," Solar Energy, vol. 84, no. 9, pp. 1685-1695, 2010.

[7] S. Janjai, J. Laksanaboonsong, M. Nunez, and A. Thongsathitya, "Development of a method for generating operational solar radiation maps from satellite data for a tropical environment," Solar Energy, vol. 78, no. 6, pp. 739-751, 2005.

[8] X. Zhang, S. Liang, G. Zhou, H. Wu, and X. Zhao, "Generating Global LAnd Surface Satellite incident shortwave radiation and photosynthetically active radiation products from multiple satellite data," Remote Sensing of Environment, vol. 152, pp. 318332, 2014.

[9] T. He, S. Liang, D. Wang, Q. Shi, and M. L. Goulden, "Estimation of high-resolution land surface net shortwave radiation from AVIRIS data: algorithm development and preliminary results," Remote Sensing of Environment, vol. 167, pp. 20-30, 2015.

[10] G. Bisht and R. L. Bras, "Estimation of net radiation from the moderate resolution imaging spectroradiometer over the continental united states," IEEE Transactions on Geoscience and Remote Sensing, vol. 49, no. 6, pp. 2448-2462, 2011.
[11] L. F. Zarzalejo, J. Polo, L. Martín, L. Ramírez, and B. Espinar, "A new statistical approach for deriving global solar radiation from satellite images," Solar Energy, vol. 83, no. 4, pp. 480-484, 2009.

[12] V. Badescu and A. Dumitrescu, "New models to compute solar global hourly irradiation from point cloudiness," Energy Conversion and Management, vol. 67, pp. 75-91, 2013.

[13] R. Festa and C. F. Ratto, "Solar radiation statistical properties," Tech. Rep., IEA Task IX, University of Genoa, Genoa, Italy, 1993.

[14] V. Badescu, "Use of sunshine number for solar irradiance time series generation," in Modeling Solar Radiation at the Earth's Surface: Recent Advances, V. Badescu, Ed., pp. 327-355, Springer, Berlin, Germany, 2008.

[15] V. Badescu and A. Dumitrescu, "Simple models to compute solar global irradiance from the CMSAF product Cloud Fractional Coverage," Renewable Energy, vol. 66, pp. 118-131, 2014.

[16] Y. Kawai and H. Kawamura, "Validation and improvement of satellite-derived surface solar radiation over the northwestern Pacific Ocean," Journal of Oceanography, vol. 61, no. 1, pp. 7989, 2005.

[17] J.-M. Yeom and K.-S. Han, "Improved estimation of surface solar insolation using a neural network and MTSAT-1R data," Computers and Geosciences, vol. 36, no. 5, pp. 590-597, 2010.

[18] M. Iqbal, An Introduction to Solar Radiation, Academic Press, New York, NY, USA, 1983.

[19] Kipp \& Zonen, “CM21 Precision Pyranometer," 2004, http://www.kippzonen.com/Download/52/CM-21-PyranometerManual?ShowInfo=true.

[20] D. A. Hastings and P. K. Dunbar, "Global land one-kilometer base elevation (GLOBE)," NGDC Key to Geophysical Records Documentation 34, 1999.

[21] H. Kawamura, S. Tanahashi, and T. Takahashi, "Estimation of insolation over the Pacific Ocean off the Sanriku Coast," Journal of Oceanography, vol. 54, no. 5, pp. 457-464, 1998.

[22] J.-M. Yeom, K.-S. Han, and J.-J. Kim, "Evaluation on penetration rate of cloud for incoming solar radiation using geostationary satellite data," Asia-Pacific Journal of Atmospheric Sciences, vol. 48, no. 2, pp. 115-123, 2012.

[23] K. S. Han, J. M. Yeom, C. S. Lee, I. C. Shin, and D. H. Kim, "Improved estimation of insolation by using calibrated COMS MI images over South Korea," Remote Sensing Letters, vol. 6, no. 3, pp. 175-182, 2015.

[24] S. Tanahashi, H. Kawamura, T. Matsuura, T. Takahashi, and H. Yusa, "A system to distribute satellite incident solar radiation in real-time," Remote Sensing of Environment, vol. 75, no. 3, pp. 412-422, 2001.

[25] J.-M. Yeom, K.-S. Hanb, Y.-S. Kim, and J.-D. Jang, "Neural network determination of cloud attenuation to estimate insolation using MTSAT-1R data," International Journal of Remote Sensing, vol. 29, no. 21, pp. 6193-6208, 2008.

[26] S. Kizu, A study on thermal response of ocean surface layer to solar radiation using satellite sensing [Ph.D. thesis], Tohoku University, Sendai, Japan, 1995.

[27] R. Frouin, D. W. Lingner, C. Gautier, K. S. Baker, and R. C. Smith, "A simple analytical formula to compute clear sky total and photosynthetically available solar irradiance at the ocean surface," Journal of Geophysical Research, vol. 94, no. 7, pp. 97319742, 1989.

[28] A. A. Lacis and J. E. Hansen, "A parameterization for the absorption of solar radiation in the Earth's atmosphere," Journal of the Atmospheric Sciences, vol. 31, no. 1, pp. 118-133, 1974. 
[29] D. Chesters, W. D. Robinson, and L. W. Uccellini, "Optimized retrievals of precipitable water from the VAS 'split windows," Journal of Climate and Applied Meteorology, vol. 26, pp. 10591066, 1987.

[30] K. Y. Kondratyev and M. P. Federova, Radiation Regime of Inclined Slopes, vol. 152 of W.M.O. Tech. Note, World Meteorological Organization, Geneva, Switzerland, 1977.

[31] J. E. Hay, "Study of shortwave radiation on non-horizontal surface," Tech. Rep. 79-12, Canadian Climate Centre, Atmospheric Environment Service, Downsview, Canada, 1979.

[32] R. G. Barry, Mountain Weather and Climate, Psychology Press, Routledge, 2nd edition, 1992.

[33] J. M. Yeom, K. S. Han, C. S. Lee, and D. Y. Kim, "An improved validation technique for the temporal discrepancy when estimated solar surface insolation compare with groundbased pyranometer: MTSAT-1R data use," Korean Journal of Remote Sensing, vol. 24, no. 6, pp. 605-612, 2008 (Korean).

[34] J. M. Yeom, K. S. Han, Y. Y. Park, and Y. S. Kim, "A representativity test on the pyranometer measurement of surface solar insolation through satellite observation," Korean Journal of Remote Sensing, vol. 22, no. 5, pp. 389-396, 2006 (Korean).

[35] G. D. Robinson, "Absorption of solar radiation by atmospheric aerosol, as revealed by measurements at the ground," Archiv für Meteorologie, Geophysik und Bioklimatologie B, vol. 12, no. 1, pp. 19-40, 1962.

[36] C. Frohlich and R. B. Wehrli, "Solar radiation and its variation," Solar Physics, vol. 74, no. 1, pp. 209-215, 1981.

[37] W. G. Paltridge and C. M. Platt, Radiative Processes in Meteorology and Climatology, Elsevier, 1976. 


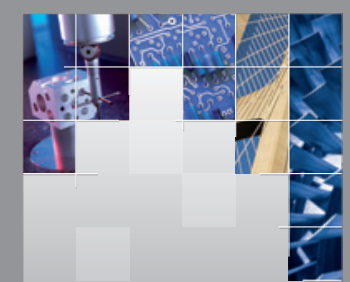

\section{Enfincering}
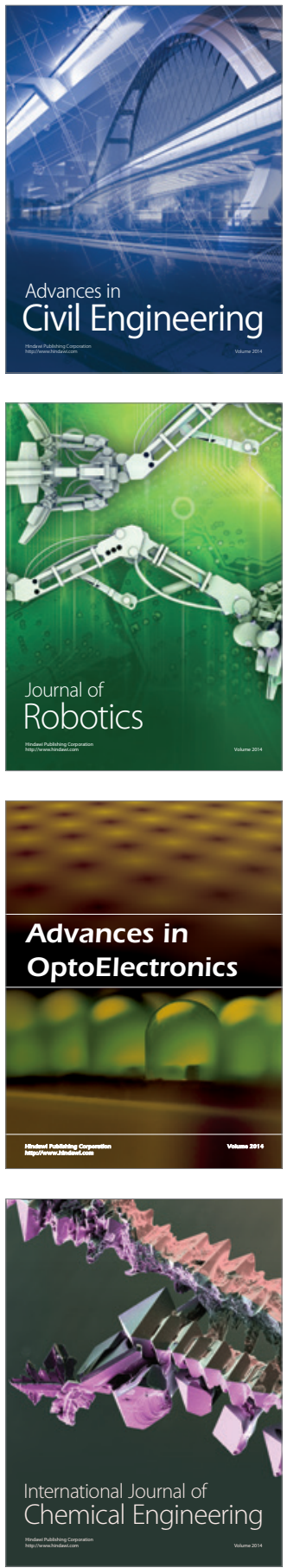

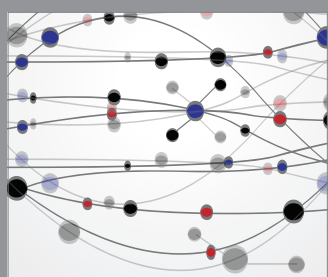

The Scientific World Journal

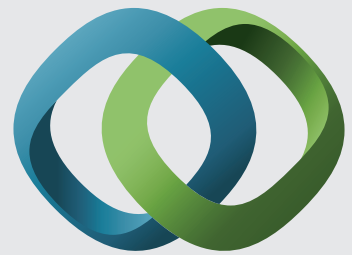

\section{Hindawi}

Submit your manuscripts at

http://www.hindawi.com
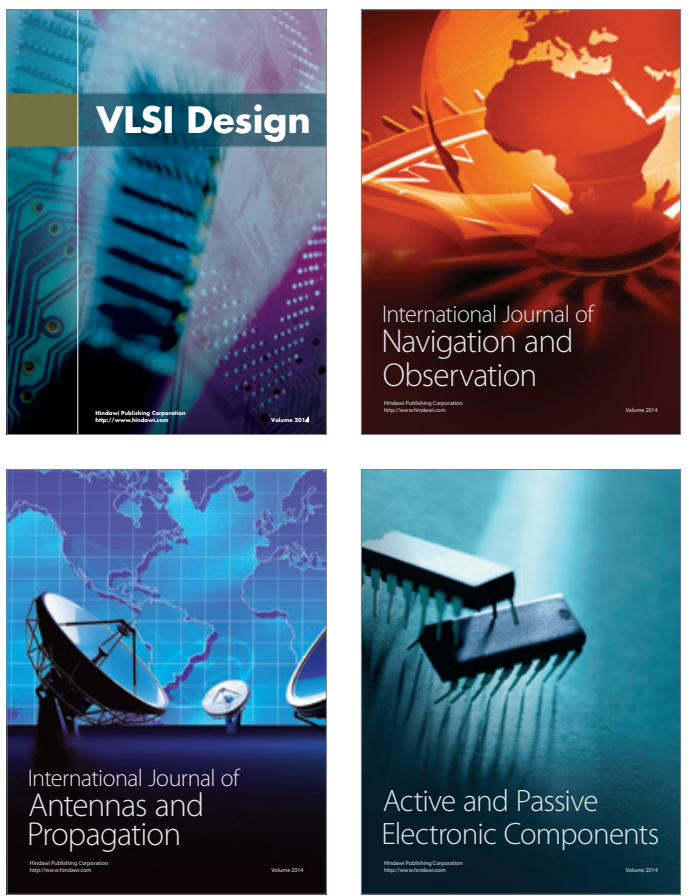
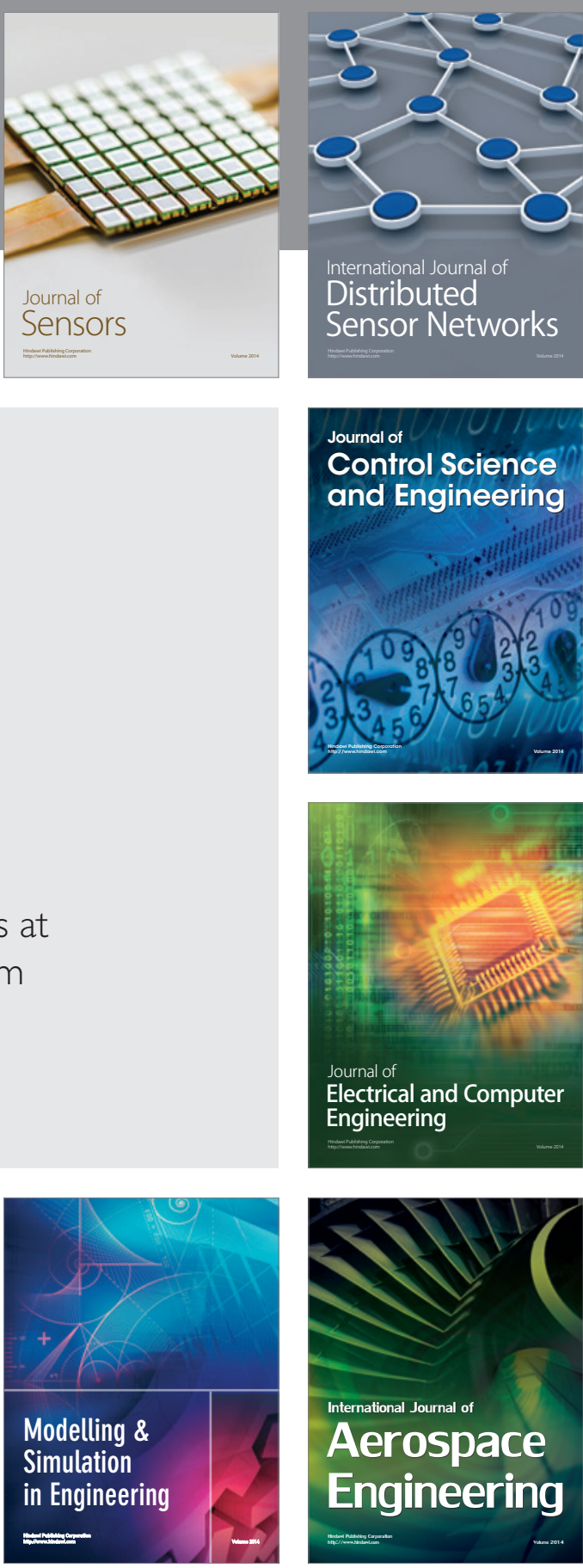

International Journal of

Distributed

Sensor Networks

Journal of

Control Science

and Engineering
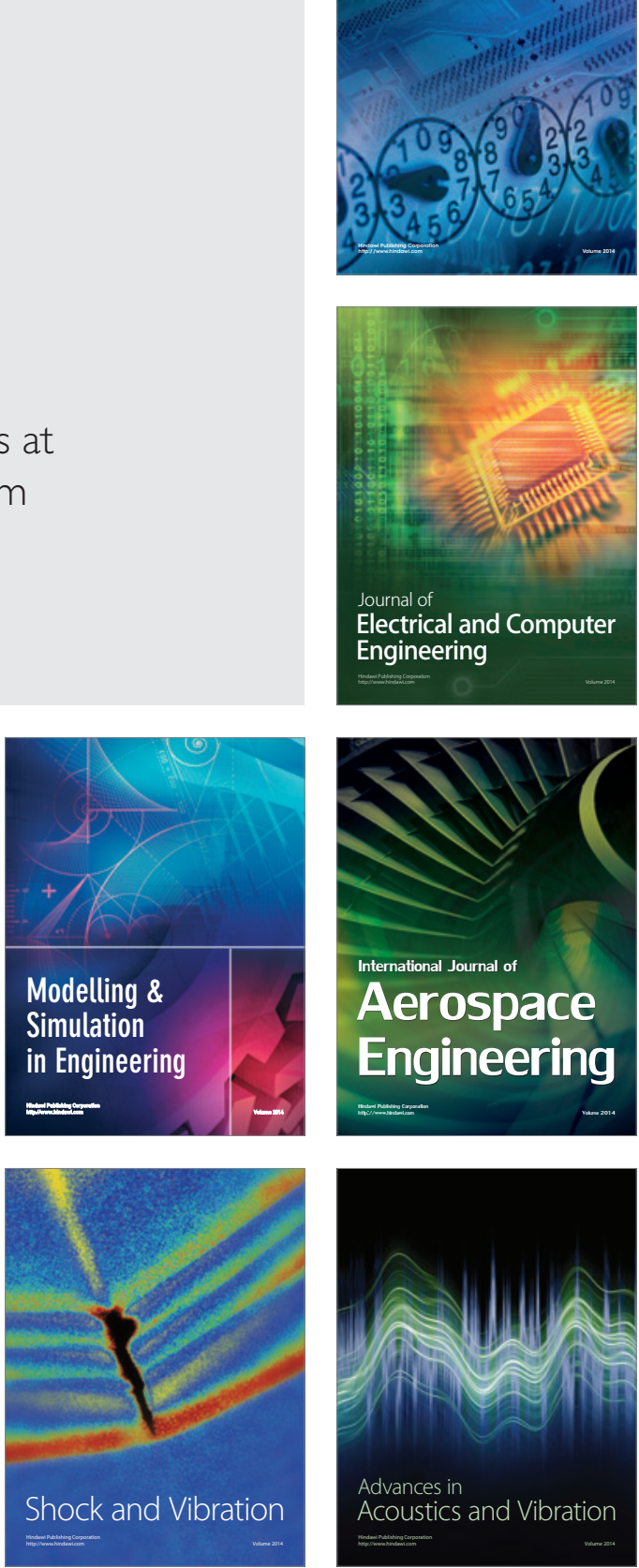